\title{
A combined neurophysiological and behavioural study into the stimulating effects of fexofenadine on performance
}

Citation for published version (APA):

Theunissen, E. L., Jonkman, L. M., Kuypers, K. P. C., \& Ramaekers, J. G. (2006). A combined neurophysiological and behavioural study into the stimulating effects of fexofenadine on performance. Journal of Psychopharmacology, 20(4), 496-505. https://doi.org/10.1177/0269881105058362

Document status and date:

Published: 01/01/2006

DOI:

10.1177/0269881105058362

Document Version:

Publisher's PDF, also known as Version of record

Document license:

Taverne

Please check the document version of this publication:

- A submitted manuscript is the version of the article upon submission and before peer-review. There can be important differences between the submitted version and the official published version of record.

People interested in the research are advised to contact the author for the final version of the publication, or visit the DOI to the publisher's website.

- The final author version and the galley proof are versions of the publication after peer review.

- The final published version features the final layout of the paper including the volume, issue and page numbers.

Link to publication

\footnotetext{
General rights rights.

- You may freely distribute the URL identifying the publication in the public portal. please follow below link for the End User Agreement:

www.umlib.nl/taverne-license

Take down policy

If you believe that this document breaches copyright please contact us at:

repository@maastrichtuniversity.nl

providing details and we will investigate your claim.
}

Copyright and moral rights for the publications made accessible in the public portal are retained by the authors and/or other copyright owners and it is a condition of accessing publications that users recognise and abide by the legal requirements associated with these

- Users may download and print one copy of any publication from the public portal for the purpose of private study or research.

- You may not further distribute the material or use it for any profit-making activity or commercial gain

If the publication is distributed under the terms of Article $25 \mathrm{fa}$ of the Dutch Copyright Act, indicated by the "Taverne" license above, 


\section{A combined neurophysiological and behavioural study into the stimulating effects of fexofenadine on performance}

Journal of Psychopharmacology 20(4) (2006) 496-505 (c) 2006 British Association for Psychopharmacology ISSN 0269-8811 SAGE Publications Ltd, London, Thousand Oaks, CA and New Delhi 10.1177/0269881105058362

Eef L. Theunissen Experimental Psychopharmacology Unit, Brain and Behaviour Institute, Faculty of Psychology, Maastricht University, Maastricht, The Netherlands.

Lisa M. Jonkman Department of Neurocognition, Faculty of Psychology, Maastricht University, Maastricht, The Netherlands.

Kim P.C. Kuypers Experimental Psychopharmacology Unit, Brain and Behaviour Institute, Faculty of Psychology, Maastricht University, Maastricht, The Netherlands.

Johannes G. Ramaekers Experimental Psychopharmacology Unit, Brain and Behaviour Institute, Faculty of Psychology, Maastricht University, Maastricht, The Netherlands.

\begin{abstract}
Antihistamines are known for their sedative effects. However, some studies suggested mild stimulant effects in the case of fexofenadine. The goals of this study are to examine whether fexofenadine possesses stimulating properties and to determine whether such stimulating effects are related to workload. Sixteen healthy volunteers received a single dose of 180 and $360 \mathrm{mg}$ fexofenadine and placebo on separate test days. Drug effects were assessed using a divided attention task (DAT), continuous performance task (CPT) and motor choice reaction time test (MCRT). Sensitivity of the tasks was increased by manipulating the workload during task performance. Event Related brain Potentials (ERPs) were measured in the DAT and CPT to study the underlying neurophysiological processes. An interaction effect of Treatment and Workload was found on tracking performance in the DAT and on movement time in the MCRT. Performance on the DAT was less affected by increments in workload
\end{abstract}

after fexofenadine as compared to placebo. P1 and P3 latency were affected by Treatment $\times$ Workload and Treatment respectively and indicated faster attentional and information processing latencies following fexofenadine treatment. Treatment did not influence performance in the CPT task or in the ERPs measured during this task. The MCRT demonstrated faster movement times following fexofenadine treatment. These results suggest that although the neurophysiological data indicate central nervous system (CNS) activation after fexofenadine treatment, the magnitude of the centrally activating effects is too small to produce relevant performance improvement at the behavioural level.

\section{Keywords}

H1-receptor antagonist, event related potentials, psychomotor performance, attention, psychostimulant

\section{Introduction}

Allergies such as allergic rhinitis, conjunctivitis and urticaria are caused by hypersensitivity to peripheral histamine. Relief of symptoms is accomplished by antihistamines which reach their therapeutic effect by blocking peripheral histamine receptors (H1). The first antihistamines developed were lipophilic and therefore entered the brain easily where they also blocked central histamine neurotransmission. Central histamine neurotransmission is involved in the maintenance of arousal (Onoe et al., 1992; Onodera et al., 1994). Blocking central H1-receptors by antihistamines has been shown to induce somnolence and to seriously diminish cognitive, psychomotor and driving performance in healthy volunteers (Rombaut and Hindmarch, 1994; Simons, 1994; O'Hanlon and Ramaekers, 1995). Other side effects of first generation antihistamines, such as diphenhydramine, triprolidine, clemastine or chlorpheniramine, are blurred vision and dry mouth as a result of muscarinic antagonism (Snyder and Snowman, 1987; Gengo, 1996; Passalacqua et al., 1996).

Second generation antihistamines (also called non-sedating antihistamines) were developed to overcome the problem of sedation. These antihistamines are less lipophilic and cross the bloodbrain barrier more slowly than their predecessors. However, recent studies have shown that also second generation antihistamines 
have the potential to cause sedation (O'Hanlon and Ramaekers, 1995). Several second generation antihistamines (acrivastine, cetirizine, mizolastine and emedastine) mildly impaired driving when given in therapeutic doses (Ramaekers and O'Hanlon, 1994; Vuurman et al., 1994; Vermeeren et al., 2002). Other second generation antihistamines (loratadine, mequitazine and terfenadine) did not have significant effects on driving performance when taken in recommended doses but had at least measurable effects after doubling the dose (Riedel et al., 1990; Theunissen et al., 2004). These results indicate that not all second generation antihistamines share the same low tendency to produce sedation.

Recently some second generation antihistamines were even found to possess stimulating effects. Fexofenadine, for instance, did not impair psychomotor and driving performance when given in single doses ranging from 60-240 $\mathrm{mg}$ (Vermeeren and O'Hanlon, 1998; Hindmarch and Shamsi, 1999; Nicholson et al., 2000; Weiler et al., 2000; Bower et al., 2003) but rather improved driving performance (Vermeeren and O'Hanlon, 1998), an effect which was previously also demonstrated for ebastine $10 \mathrm{mg}$ (O'Hanlon and Ramaekers, 1995). Single doses of desloratadine 5 $\mathrm{mg}$ also did not cause impairing effects on actual driving and psychomotor performance but did improve brake reaction time in the driving test (Vuurman et al., 2004). Terfenadine is yet another antihistamine which has shown not to impair performance but rather improve performance on psychomotor tasks (Moskowitz and Burns, 1988) and subjective alertness and wakefulness (Clarke and Nicholson, 1978; Reinberg et al., 1978). Improved psychomotor performance and body balance were also found after single doses of ebastine (Mattila et al., 1992). The clinical significance of these findings is unclear, but they indicate that these antihistamines do enter the brain and can cause stimulating effects.

The goals of this study are to examine whether fexofenadine possesses stimulating properties and to assess whether its stimulating effects are related to workload. It is expected that tasks with a high workload are more sensitive for a stimulating drug effect. Dependent variables include behavioural measures as well as Event Related brain Potentials (ERPs). ERPs are particularly useful for measuring temporal and cognitive information processes that precede an overt, behavioural response.

\section{Materials and methods}

\section{Subjects}

Sixteen healthy volunteers (eight males and eight females), aged between 21 and 35 years were recruited by means of newspaper advertisements. Subjects were first screened using a medical history questionnaire. Each qualified subject underwent a physical examination in which an electrocardiogram was made and a blood sample was taken. Mean (SD) age of the participants was 23.3 (3.19) years.

Exclusion criteria were: history of major medical or psychiatric disorder, any non-corrected visual or psychomotor defect, unusual sensitivity to antihistamines, drug abuse and chronic use of medication. Female subjects could not participate when pregnant or lactating, and were required to use an effective contraceptive during the study. After having received all necessary information, every participant gave their written consent. The study was approved by the medical Ethical Committee of Maastricht University and subsequently carried out in accordance with the World Medical Associations Declaration of Helsinki (Edinburgh modification, 2000).

\section{Procedure}

Drugs and placebo were administered according to a three-way, double-blind, cross-over design. A wash-out period of at least 7 days proceeded in between treatments. Treatments consisted of single doses of placebo, fexofenadine $180 \mathrm{mg}$ and fexofenadine $360 \mathrm{mg}$ (therapeutic dose of fexofenadine is $120-180 \mathrm{mg}$ ). Drugs and placebo were administered in orally identically appearing formulations to ensure blinding.

All subjects were trained on all tests a few days prior to their first treatment period. Subjects were prohibited from consuming alcohol for $24 \mathrm{~h}$ before testing. Half an hour before drug intake all subjects received a standard meal. Consumption of caffeine-containing beverages was not allowed on test days. Smoking was prohibited 30 minutes prior to and during testing. Behavioural and ERP testing were performed between 2 and $3 \mathrm{~h}$ after drug intake.

\section{Assessments}

Critical tracking task (CTT) In the critical tracking task, the subject controls an unstable cursor on a computer screen using a joystick (Jex et al., 1966). An error signal causes the cursor to become increasingly unstable on a horizontal axis, causing it to diverge from the centre of the axis. The subject's task is to try to keep the cursor in the centre of the axis by continuously making compensatory joystick movements. The frequency of cursor deviations increases as a stochastic, linear function of time, and therefore the subject is required to make compensatory movements with a progressively higher frequency. Eventually, the subject's response adds to, rather than subtracts from, the error and consequently control is lost. The frequency at which the subject loses the control is the critical frequency $(\lambda c)$. The test is performed five times; the average critical frequency is calculated without the lowest and highest score and is the dependent variable of this test. Depending on the competence of the subject, this task takes 3 to $8 \mathrm{~min}$.

Divided attention task (DAT) The DAT measures the ability to divide attention between two simultaneous tasks (Moskowitz, 1973). As a primary task, the subject performs the same tracking task as described above but at a constant level of difficulty. The task is repeated three times, each with the primary task set at a different level of difficulty in order to assess the interaction between mental workload and drug treatment. Task difficulties $(\lambda c)$ are set at 50,60 and $70 \%$ of each subject's maximal performance as measured during training sessions of critical tracking task. As a secondary task, the subject monitors a central display upon which single digits ( 0 to 9 ) are presented for 17 milliseconds with a variable inter-stimulus interval between 1.03 and 1.23 seconds. The occurrence of the digit ' 2 ' is a signal for the subject to remove 
his/her foot from a pedal as rapidly as possible. In total, 75 targets and 375 distractors are presented. Mean absolute tracking error $(\mathrm{mm})$ is the dependent variable in the primary task; number of correct responses and mean reaction time $(\mathrm{ms})$ of these responses are the performance measures in the secondary task. Depending on the competence of the subject, this task takes about $10 \mathrm{~min}$.

It is hypothesized that performance in the primary task will decline as a result of the increased workload and in addition performance on the secondary task will be negatively influenced by the increased workload of the primary task.

Continuous performance task (CPT) CPTs (Conners, 1992) have been used repeatedly to study vigilance and attention, and several variants of this test have been developed. The version used in the present experiment is the CPT-ax task. In this task, letters are presented to the subject one by one on a computer screen for $150 \mathrm{msec}$ with an Inter Stimulus Interval (ISI) of $600 \mathrm{msec}$. The subject's task is to press a button as fast as possible when the target letter X appears, but only when it is preceded by an A (Go condition). In situations in which the cue letter A is not followed by the target $\mathrm{X}$, subjects have to inhibit their prepared responses (NoGo condition). Thus, the task measures attention associated with Go responses as well as inhibition processes (evoked by NoGo trials). The task included 48 Go stimuli (A-X), 96 NoGo trials (A-nontarget) and 240 randomly presented letters. Nontarget letters were $\mathrm{E}, \mathrm{H}, \mathrm{L}$ and $\mathrm{K}$. The task was divided into four blocks and lasted in total approximately $10 \mathrm{~min}$.

In order to differentiate workload conditions in the CPT-ax task a high load version was developed. In this version, the target letter is an $\mathrm{X}$ with a small dot on top of it. The letter $\mathrm{X}$ with a small dot underneath was added as a nontarget, and had to be ignored. In total this task included 48 Go trials (A-X-dot on top), 144 NoGo trials (48 A-X-dot below and 96 A-nontarget) and 288 randomly presented letters. Except for the changed target letter and the added nontarget, the task is identical to the easy version. The variables measured in both tasks are number of correct responses, number of false alarms and reaction time of these responses.

Motor choice reaction time (MCRT) The MCRT is a test in which reaction time is studied as a function of task difficulty (Houx and Jolles, 1993). The subject is presented with a computerized panel with one central red and five white buttons. The subject is asked to hold the central red button until one of the white buttons lights up. As soon as a white button illuminates, the participant has to release the red button and press the illuminated button and return to the red central button as fast as possible. Three task conditions with increasing difficulty were used: simple reaction time, in which only the upper button illuminates; choice reaction time, in which one of a defined set of three buttons illuminates; and incompatible reaction time, which is the same as the previous condition but the task is to press the button located to the right of the illuminated button. Reaction time was divided into an initiation phase, i.e. time from stimulus onset until release of the red button, and a movement phase, i.e. time between release of the red button and pressing the response button. Initiation time repre- sents the time needed for perception, decision and motor planning while movement time represents the time needed for actual movement execution. Dependent measures are median initiation and movement time in the three workload conditions (simple, choice and incompatible condition). Task duration is approximately 3 $\min$.

\section{Event related potentials Recording}

EEG-activity was recorded by means of an electro-cap from an array of 30 electrodes from the standard 10-20 system $(F z, C z, P z$, $\mathrm{Oz}, \mathrm{F3}, \mathrm{F4}, \mathrm{F7}, \mathrm{F} 8, \mathrm{C3}, \mathrm{C4}, \mathrm{T3}, \mathrm{T4}, \mathrm{T5}, \mathrm{T6}, \mathrm{P3}, \mathrm{P4}, \mathrm{O1}, \mathrm{O} 2, \mathrm{Fp} 1$, $F p 2, F t 7, F t 8, F c 3, F c 4, T p 7, T p 8, C p 3, C p 4, F C z, C P z)$. Electrodes were filled with electro-gel. All electrodes were referenced to the left mastoid; FPz was used as ground electrode. Horizontal EOG was recorded using electrodes attached to the outer canthi of the eyes, while vertical EOG were recorded from infraorbital and supraorbital electrodes placed in line with the pupil of the left eye. All electrode impedances were kept below $5 \mathrm{~K} \Omega$. ERP's were collected using the Neuroscan 4.1 software, and SynAmps amplifiers were used. All signals were continuously sampled at a rate of $250 \mathrm{~Hz}$ and digitally filtered online with a high-pass filter of $0.05 \mathrm{~Hz}$ and a low-pass filter of $50 \mathrm{~Hz}$. Continuous signals were epoched into $1200 \mathrm{msec}$ sweeps for the divided attention task and into $950 \mathrm{msec}$ sweeps in the CPT-ax tasks, both including a $200 \mathrm{msec}$ pre-stimulus baseline.

\section{Signal Analysis}

All of the sampled EEG and EOG epochs were baseline corrected and filtered offline using a $30 \mathrm{~Hz}, 24 \mathrm{~dB}$ /oct digital low-pass filter. EEGs were corrected for vertical eye movements according to a procedure by Semlitsch et al., 1986. Sweeps containing an artifact exceeding +75 or $-75 \mu \mathrm{V}$ were rejected.

\section{ERP-components}

The ERP-components of interest in the tasks used are the occipital P1, the frontal N2 and parietal P3 (or P3b). P1 is a positive peak which appears around $100 \mathrm{msec}$, above visual cortex and reflects early attentional processes (Mangun and Hillyard, 1990; Mangun, 1995), and is specifically sensitive to spatial attributes of the stimulus (Rugg et al., 1987), task load and salience (Taylor, 2002). In Go/NoGo tasks, the N2 wave (a negative wave occurring around $200 \mathrm{msec}$ post-stimulus) is reported to be related to response inhibition (Jodo and Kayama, 1992; Falkenstein et al., 1999). The parietal P3, a positive wave between 300 and $800 \mathrm{msec}$, has mostly been demonstrated in so-called oddball tasks (Picton, 1992; Polich and Kok, 1995). In these kinds of tasks, subjects are presented with frequent and rare stimuli in a random order. P3 amplitude is shown to be affected by the probability of the rare stimulus (Duncan-Johnson and Donchin, 1977), in both passive and active tasks (Mertens and Polich, 1997). Other factors like attention, stimulus quality and task relevance also appear to affect P3 amplitude (Smulders et al., 1995). The P3 component has also previously shown to be an indicator for processing capacity in dual tasks. P3 elicited by a secondary test, has been found to decrease in amplitude with increases in the perceptual or cognitive 
difficulty of the primary task (Isreal et al., 1980; Wickens et al., 1983; Brocke et al., 1996; Kok, 2001). On the other hand, P3 latency of the secondary task is affected mainly by stimulus evaluation time of the primary task (Duncan-Johnson, 1981; Smulders et al., 1995).

In the dual-task (divided attention task), ERPs were measured in relation to the secondary task. ERP-averages for individual subjects were calculated for targets and distractors. Artifact-free epochs ranged between 60 and 75 for targets and between 300 and 375 for distractors. Parietal (Pz) P3 peak amplitude and latency was determined in a window between 350 and $650 \mathrm{msec}$ as a measure of the amount of invested capacity in the secondary task under different workload conditions. It is expected that the P3 amplitude will decrease as a function of workload because of the diminished capacity available for the secondary task. Furthermore, the maximum P1 amplitude and latency at $\mathrm{Oz}$ was scored between 80 and $200 \mathrm{msec}$ to examine effects of primary task load on early attentional processing of stimuli in the secondary task.

For the easy CPT-ax version, individual ERP averages were calculated for correctly detected targets, for correctly rejected nontargets following A that shared no features with the target letter (E, H, L), and for the correctly rejected nontarget letter K following $\mathrm{A}$, which has similarities with the target letter. For the harder CPT-ax task, averages were calculated for correctly detected targets (X-dot on top following A) and three types of correctly rejected distractors (random letters $(\mathrm{E}, \mathrm{H}, \mathrm{L}), \mathrm{K}$ and $\mathrm{X}$-dot below, all following the cue letter A). All ERPs were calculated based on at least 23 and maximum 48 artifact-free epochs. In both tasks the maximum amplitude and peak latency of the frontal N2 (Fz) was measured between 150 and $350 \mathrm{msec}$ following onset of the stimulus as an indicator of response inhibition which is expected to be larger in distractor than target conditions. The maximum parietal P3 peak and its latency were measured at Pz between 250 and $600 \mathrm{msec}$ after stimulus onset and was taken as a measure of attention invested in the processing of targets (compared to nontargets). All time windows were defined after inspection of the grand averages.

\section{Analysis}

All parameters that were normally distributed were subjected to a repeated measures analysis of variance (ANOVA). Performance data from the DAT were tested for the main effects of Treatment (three levels), Workload (three levels) and Treatment by Workload. ERP data were tested for an additional factor Stimulus-type (two levels). Performance and ERP data from the CPT tasks were tested for the main effect of Treatment in the easy and high load conditions separately. ERP analysis also included the additional factor Stimulus-type (three levels in the easy version and four levels in the difficult version). Performance data from the MCRT task were tested for the effects of Treatment (three levels) and Workload (three levels). Type I errors associated with inhomogeneity of variance were controlled by decreasing the degrees of freedom using GreenhouseGeisser corrections, and the probability estimates were based on these reduced degrees of freedom. Separate drug-placebo com- parisons were conducted only in case of a significant main effect of Treatment or Treatment $\times$ Workload by means of simple contrasts with Bonferroni correction. The main variables of the divided attention task (RT, tracking error and P3) were tested 1tailed because of the one-sided nature of the prediction. All other evaluations were carried out in a similar fashion, but were tested two-tailed and significance level was $p<0.05$ in all cases. Variables that were not normally distributed were analysed using the non-parametric Friedman test. All statistical tests were conducted using SPSS (version 10.0).

\section{Results}

A summary of descriptive and quantitative statistical analyses of the behavioural results in each treatment condition are shown in Table 1, and of ERP measures in each treatment are shown in Table 2.

\section{CTT}

There was no effect of Treatment on CTT.

\section{DAT}

In the primary task of the DAT, tracking error was significantly affected by Workload level $\left(\mathrm{F}_{2,30}=128.1 p<0.01\right.$, one sided $)$, i.e. tracking error increased when workload increased. There was no main effect of Treatment, but the interaction between Treatment and Workload reached significance $\left(\mathrm{F}_{1,15}=4.47 ; p=0.026\right)$. As can be seen in Table 1, the increase in tracking error in the two hardest workload conditions was less during fexofenadine treatment as compared to placebo. Additional analyses employing difference scores from the two highest workload conditions versus the easiest workload condition provided further support for this notion as indicated by an overall effect of Treatment $\left(\mathrm{F}_{2,30}=2.948 ; p=0.034\right)$. Separate drug-placebo contrasts furthermore revealed that increments in tracking error were less after fexofenadine $360 \mathrm{mg}$ as compared to placebo $\left(\mathrm{F}_{1,15}=4.793\right.$; $p=0.023$ ). Mean increments of tracking error in the highest workload conditions for each treatment are shown in Fig. 1. Reaction time and the number of hits were not significantly affected by Treatment.

ERP P1 latency demonstrated significant effects of Treatment $\times$ Workload $\left(\mathrm{F}_{4,60}=3.03 ; p=0.024\right)$ and Stimulus-type $\left(\mathrm{F}_{1,15}=20.0 ; p<0.01\right)$. The Treatment $\times$ Workload interaction indicated that while workload augmented, P1 latency increased in the placebo condition, but decreased in the fexofenadine conditions (see Fig. 4). P1 amplitude was only affected by Stimulustype $\left(\mathrm{F}_{1,15}=4.55 ; p=0.05\right)$.

P3 latency revealed significant main effects of Treatment $\left(\mathrm{F}_{2,30}=4.5 ; p=0.02\right)$, Stimulus-type $\left(\mathrm{F}_{1,15}=17.2 ; p<0.01\right)$ and Workload $\left(\mathrm{F}_{2,30}=5.6 ; p<0.01\right)$. P3 latency occurred earlier after fexofenadine $360 \mathrm{mg}$ as compared to placebo $\left(\mathrm{F}_{1,15}=8.8\right.$; $p<0.01)$. However, there were no interactions between Treatment $\times$ Workload or Treatment $\times$ Stimulus-type on P3 
Table 1 Summary of the results on the critical tracking task, divided attention task, continuous performance task and motor choice reaction task. Treatments are placebo, fexofenadine $180 \mathrm{mg}$ (fexo 180) and fexofenadine $360 \mathrm{mg}$ (fexo 360). NS: not significant; df: degrees of freedom.

\begin{tabular}{|c|c|c|c|c|c|c|c|c|c|c|}
\hline & \multicolumn{3}{|c|}{ Mean \pm SEM per treatment } & \multicolumn{3}{|c|}{ Treatment effect } & \multicolumn{4}{|c|}{ Treatment $\times$ Workload } \\
\hline & Placebo & Fexo 180 & Fexo 360 & $\mathrm{~F}$ & $x^{2}$ & $d f$ & $\mathrm{p}$ & $\mathrm{F}$ & $\mathrm{df}$ & $\mathrm{p}$ \\
\hline \multicolumn{11}{|l|}{ СТT } \\
\hline Lambda-C (rad/sec) & $4.31 \pm 0.16$ & $4.34 \pm 0.15$ & $4.35 \pm 0.14$ & 0.48 & - & 2,30 & NS & & & \\
\hline \multicolumn{11}{|l|}{ DAT } \\
\hline Tracking error (mm) & $14.0 \pm 0.8$ & $13.0 \pm 0.8$ & $13.2 \pm 0.7$ & 0.87 & - & 2,60 & NS & 4.47 & 1,15 & 0.026 \\
\hline Workload 50 & $10.7 \pm 0.9$ & $10.1 \pm 1.1$ & $10.7 \pm 1.0$ & & & & & & & \\
\hline Workload 60 & $13.6 \pm 1.1$ & $13.1 \pm 1.3$ & $12.7 \pm 0.9$ & & & & & & & \\
\hline Workload 70 & $17.6 \pm 1.3$ & $15.9 \pm 1.3$ & $16.2 \pm 1.1$ & & & & & & & \\
\hline Reaction time (msec) & $557 \pm 11$ & $561 \pm 12$ & $562 \pm 11$ & - & 0.13 & 2 & NS & - & - & - \\
\hline Workload 50 & $560 \pm 20$ & $559 \pm 20$ & $572 \pm 17$ & & & & & & & \\
\hline Workload 60 & $550 \pm 22$ & $563 \pm 22$ & $551 \pm 18$ & & & & & & & \\
\hline Workload 70 & $561 \pm 18$ & $562 \pm 20$ & $565 \pm 21$ & & & & & & & \\
\hline Hits (\#) & $72.1 \pm 0.6$ & $71.6 \pm 0.7$ & $71.8 \pm 0.6$ & - & 0.90 & 2 & NS & - & - & - \\
\hline Workload 50 & $72.4 \pm 0.9$ & $71.6 \pm 1.0$ & $72.1 \pm 0.7$ & & & & & & & \\
\hline Workload 60 & $72.3 \pm 1.2$ & $72.5 \pm 0.9$ & $72.2 \pm 1.0$ & & & & & & & \\
\hline Workload 70 & $71.4 \pm 1.0$ & $70.6 \pm 1.7$ & $70.9 \pm 1.4$ & & & & & & & \\
\hline \multicolumn{11}{|l|}{ CPT } \\
\hline \multicolumn{11}{|l|}{ Easy load } \\
\hline Hits (\#) & $45.9 \pm 0.7$ & $46.9 \pm 0.6$ & $46.9 \pm 0.6$ & - & 4.78 & 2 & NS & & & \\
\hline Reaction time (msec) & $380 \pm 15$ & $371 \pm 13$ & $382 \pm 12$ & 1.90 & - & 2,30 & NS & & & \\
\hline \multicolumn{11}{|l|}{ High load } \\
\hline Hits $(\#)$ & $46.9 \pm 0.4$ & $46.1 \pm 0.8$ & $46.7 \pm 0.5$ & - & 1.59 & 2 & NS & & & \\
\hline Reaction time (msec) & $398 \pm 13$ & $392 \pm 14$ & $411 \pm 13$ & 3.28 & - & 2,30 & 0.051 & & & \\
\hline \multicolumn{11}{|l|}{ MCRT } \\
\hline Initiation time (msec) & $344 \pm 8$ & $341 \pm 8$ & $342 \pm 11$ & 0.61 & - & 2,56 & NS & 2.52 & $2.6,36.6$ & NS \\
\hline Simple & $298 \pm 7$ & $292 \pm 6$ & $303 \pm 13$ & & & & & & & \\
\hline Choice & $336 \pm 7$ & $334 \pm 9$ & $337 \pm 10$ & & & & & & & \\
\hline Incompatible & $399 \pm 11$ & $398 \pm 12$ & $389 \pm 12$ & & & & & & & \\
\hline Movement time (msec) & $102 \pm 6$ & $97 \pm 6$ & $101 \pm 5$ & 2.08 & - & 2,56 & NS & 2.58 & 4,56 & 0.047 \\
\hline Simple & $104 \pm 6$ & $97 \pm 6$ & $98 \pm 6$ & & & & & & & \\
\hline Choice & $98 \pm 6$ & $97 \pm 6$ & $101 \pm 5$ & & & & & & & \\
\hline Incompatible & $105 \pm 6$ & $99 \pm 6$ & $104 \pm 5$ & & & & & & & \\
\hline
\end{tabular}

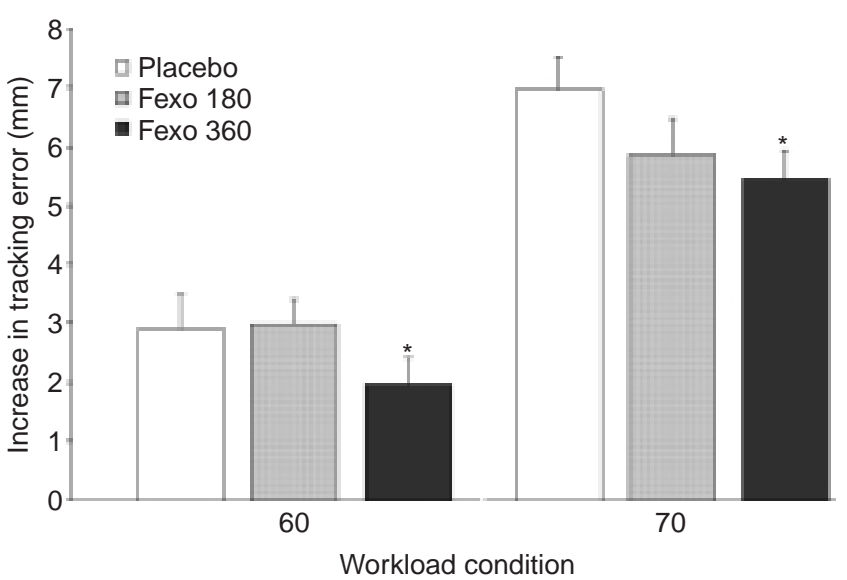

Figure $1 \quad \Delta$ tracking error $(\mathrm{mm})$ in the divided attention task for workload 60 and 70 condition and for each treatment; placebo, fexofenadine $180 \mathrm{mg}$ (fexo 180) and fexofenadine $360 \mathrm{mg}$ (fexo 360). *Significant $(p<0.05)$ drug-placebo differences pooled over workload. latency. For P3 amplitude there was only an effect of Stimulustype $\left(F_{1,15}=96.0 ; p<0.001\right)$, with amplitudes being larger for targets. P1 and P3 grand averages recorded in each treatment and workload condition are given in Figs 2 and 3 respectively. P1 and P3 latencies as a function of workload and dose are shown in Fig. 4.

\section{CPT}

There was no significant effect of Treatment on the percentage of correctly detected targets or hit reaction time in the easy CPT-ax. In the difficult version there was an almost significant overall effect of fexofenadine on hit reaction time $\left(\mathrm{F}_{2,30}=3.28\right.$; $p=0.051)$. Mean scores demonstrated that subjects in the fexofenadine $180 \mathrm{mg}$ condition responded fastest, followed by placebo and then by fexofenadine $360 \mathrm{mg}$. However, further testing with simple contrasts did not yield significant differences between drug conditions. Other parameters of the CPT tasks showed no significant effects of the factor Treatment. 
Table 2 Summary of ERP latencies and amplitudes in the divided attention task and continuous performance tasks. Treatments are placebo, fexofenadine $180 \mathrm{mg}$ (fexo 180) and fexofenadine $360 \mathrm{mg}$ (fexo 360). NS: not significant; df: degrees of freedom.

\begin{tabular}{|c|c|c|c|c|c|c|c|c|c|}
\hline & \multicolumn{3}{|c|}{ Mean \pm SEM per treatment } & \multicolumn{3}{|c|}{ Treatment effect } & \multicolumn{3}{|c|}{ Treatment $\times$ Workload } \\
\hline & Placebo & Fexo 180 & Fexo 360 & $\mathrm{~F}$ & $\mathrm{df}$ & $\mathrm{p}$ & $\mathrm{F}$ & $\mathrm{df}$ & $\mathrm{p}$ \\
\hline \multicolumn{10}{|l|}{ DAT } \\
\hline P1-latency (msec) & $137.7 \pm 2.8$ & $137.7 \pm 2.7$ & $135.9 \pm 2.6$ & 0.57 & 2,30 & NS & 3.03 & 4,60 & 0.024 \\
\hline Targets & $138.2 \pm 0.3$ & $136.0 \pm 2.9$ & $133.3 \pm 2.8$ & & & & & & \\
\hline Nontargets & $137.3 \pm 3.1$ & $139.4 \pm 3.0$ & $138.4 \pm 2.9$ & & & & & & \\
\hline P1-amplitude $(\mu \mathrm{V})$ & $4.5 \pm 0.3$ & $4.3 \pm 0.2$ & $4.4 \pm 0.3$ & 0.54 & 2,30 & NS & 0.81 & 4,60 & NS \\
\hline Targets & $4.8 \pm 0.3$ & $4.4 \pm 0.3$ & $4.7 \pm 0.4$ & & & & & & \\
\hline Nontargets & $4.1 \pm 0.3$ & $4.2 \pm 0.2$ & $4.1 \pm 0.3$ & & & & & & \\
\hline P3-latency (msec) & $511.7 \pm 6.6$ & $504.5 \pm 7.1$ & $493.0 \pm 6.4$ & 4.492 & 2,30 & 0.02 & 1.33 & 4,60 & NS \\
\hline Targets & $484.3 \pm 6.7$ & $477.1 \pm 7.8$ & $471.3 \pm 6.7$ & & & & & & \\
\hline Nontargets & $539.1 \pm 9.0$ & $532.0 \pm 9.2$ & $514.7 \pm 9.6$ & & & & & & \\
\hline P3-amplitude $(\mu \mathrm{V})$ & $8.7 \pm 0.5$ & $8.2 \pm 0.5$ & $8.4 \pm 0.5$ & 0.87 & 2,30 & NS & 0.46 & 4,60 & NS \\
\hline Targets & $14.6 \pm 0.8$ & $13.7 \pm 0.9$ & $13.9 \pm 0.8$ & & & & & & \\
\hline Nontargets & $2.8 \pm 0.2$ & $2.7 \pm 0.2$ & $2.8 \pm 0.3$ & & & & & & \\
\hline \multicolumn{10}{|l|}{ CPT } \\
\hline \multicolumn{10}{|l|}{ Easy load } \\
\hline N2-latency (msec) & $263.9 \pm 5.0$ & $267.8 \pm 4.6$ & $265.2 \pm 5.4$ & 1.044 & 2,30 & NS & & & \\
\hline N2-amplitude $(\mu \mathrm{V})$ & $-2.2 \pm 0.6$ & $-2.4 \pm 0.8$ & $-2.6 \pm 0.8$ & 0.444 & 2,30 & NS & & & \\
\hline P3-latency (msec) & $376.5 \pm 4.3$ & $376.4 \pm 4.7$ & $380.9 \pm 4.5$ & 0.51 & 2,30 & NS & & & \\
\hline P3-amplitude $(\mu \mathrm{V})$ & $13.0 \pm 1.0$ & $14.4 \pm 1.0$ & $12.7 \pm 1.0$ & 3.14 & 2,30 & 0.058 & & & \\
\hline \multicolumn{10}{|l|}{ High load } \\
\hline N2-latency (msec) & $272.8 \pm 3.6$ & $274.5 \pm 3.5$ & $274.1 \pm 3.6$ & 0.286 & 2,30 & NS & & & \\
\hline N2-amplitude $(\mu \mathrm{V})$ & $-1.2 \pm 0.5$ & $-1.9 \pm 0.5$ & $-2.0 \pm 0.6$ & 1.041 & 2,30 & NS & & & \\
\hline P3-latency (msec) & $406.8 \pm 5.7$ & $404.8 \pm 5.8$ & $405.6 \pm 4.9$ & 0.133 & 2,30 & NS & & & \\
\hline P3-amplitude $(\mu \mathrm{V})$ & $13.2 \pm 0.9$ & $13.8 \pm 0.9$ & $13.3 \pm 0.9$ & 0.463 & 2,30 & NS & & & \\
\hline
\end{tabular}

As mentioned earlier, parietal P3 and frontal N2 ERP components were determined in Go (target) and NoGo (distractor) conditions. No Treatment effects were found for P3 or N2 components. A main effect of Stimulus-type was found for parietal P3 latency in the easy version $\left(\mathrm{F}_{2,30}=4.9 ; p=0.015\right)$ and the difficult version $\left(\mathrm{F}_{3,45}=6.4 ; p<0.001\right)$. In both versions of the CPT-ax task, an effect of Stimulus-type on latency $\left(\mathrm{F}_{1.5,22.1}=28.2\right.$; $p<0.001)$ and amplitude $\left(\mathrm{F}_{2,30}=44.0 ; p<0.001\right)$ of the frontal N2 was found.

\section{MCRT}

There was no main effect of Treatment on initiation time or movement time. However the interaction between Treatment $\times$ Workload (task difficulty) did significantly affect movement time $\left(\mathrm{F}_{4,56}=2.58 ; p=0.047\right)$. The interaction indicated that fexofenadine produces faster movement times in the Simple RT and the Incompatible RT conditions, relative to placebo. Drug-placebo contrasts showed that fexofenadine $180 \mathrm{mg}$ produced a significantly faster movement time than placebo $\left(\mathrm{F}_{1,14}=6.53 ; p<0.025\right)$.

\section{Discussion}

Previous studies found that, in contrast to most second generation antihistamines, fexofenadine does not produce sedative effects (Hindmarch et al., 1999; Bower et al., 2003; Ridout et al., 2003) and one study even suggested small stimulating effects after fexofenadine treatment (Vermeeren and O'Hanlon, 1998). In the present study the stimulating effects of fexofenadine were investigated using behavioural and electrophysiological measures.

The behavioural results of the divided attention task in this study showed that the primary tracking task was affected by workload. Increasing the workload caused the subjects to have more trouble keeping the cursor stable, resulting in an increase in tracking error. In addition, after treatment with fexofenadine tracking error increased less as a function of workload. There was no effect of fexofenadine on the behavioural results of the secondary task of the divided attention task.

Due to the nature of the task, ERPs could only be measured in relation to the secondary task of the divided attention task. The ERP data showed that brain activity in the secondary task of the 

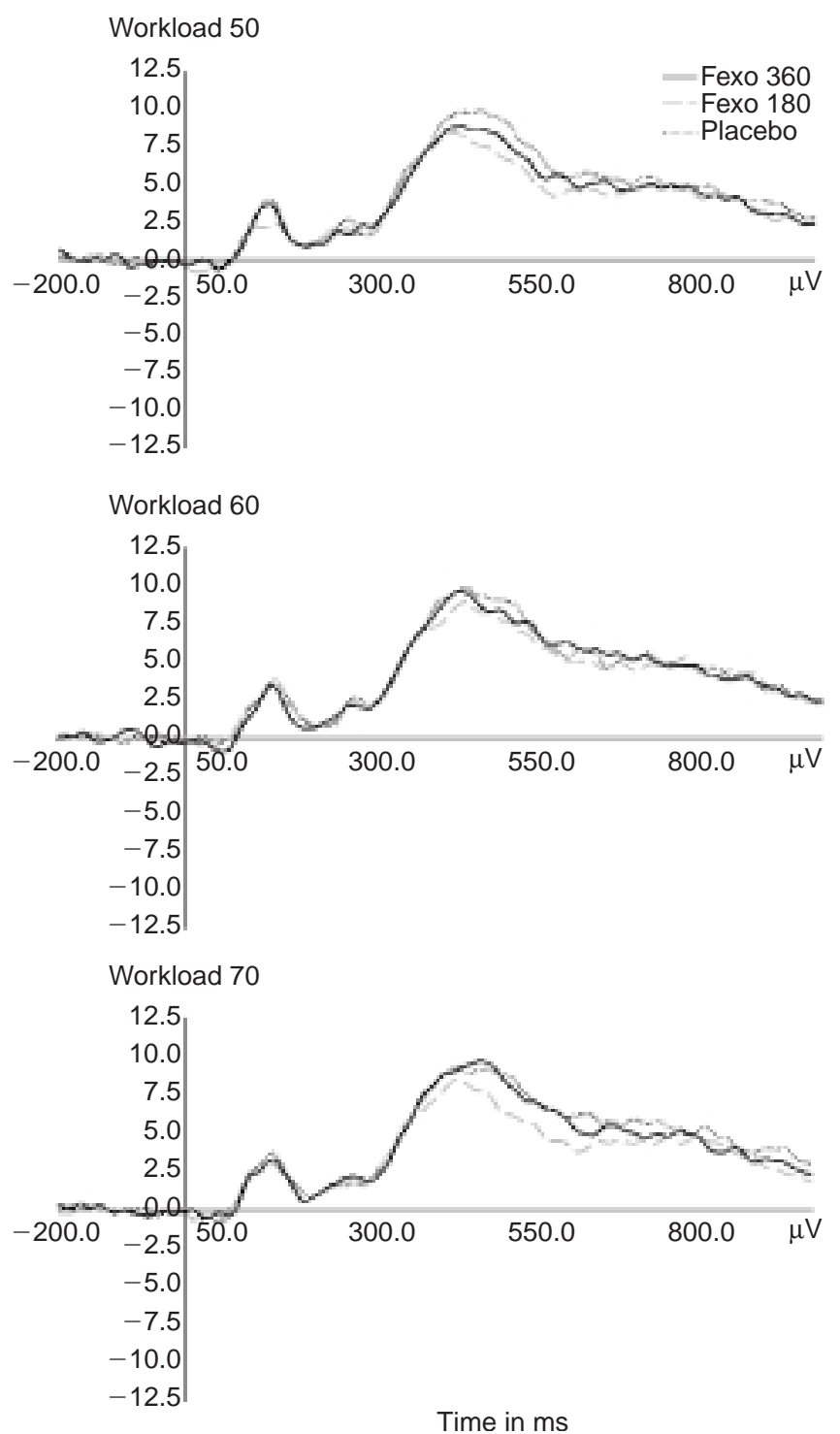

Figure 2 Grand average ERPs showing P1 at $0 z$ for targets and for workload 50, 60 and 70 of the divided attention task. Abbreviations as in Fig. 1.

DAT was significantly affected by fexofenadine and workload. Spatial attention studies have earlier demonstrated that P1-latency reflects the timing of early attentional processes (Mangun and Hillyard, 1990, 1995). In the present study, P1 amplitude was larger for targets than distractors, indicating an attention effect in a non-spatial attention test. P1-latency increased as a function of workload when subjects were treated with placebo but the opposite happened in the fexofenadine condition. It appears that especially the timing of early attentional processing is affected by the task difficulty by being delayed when the task gets harder. However, when treated with fexofenadine, this early processing
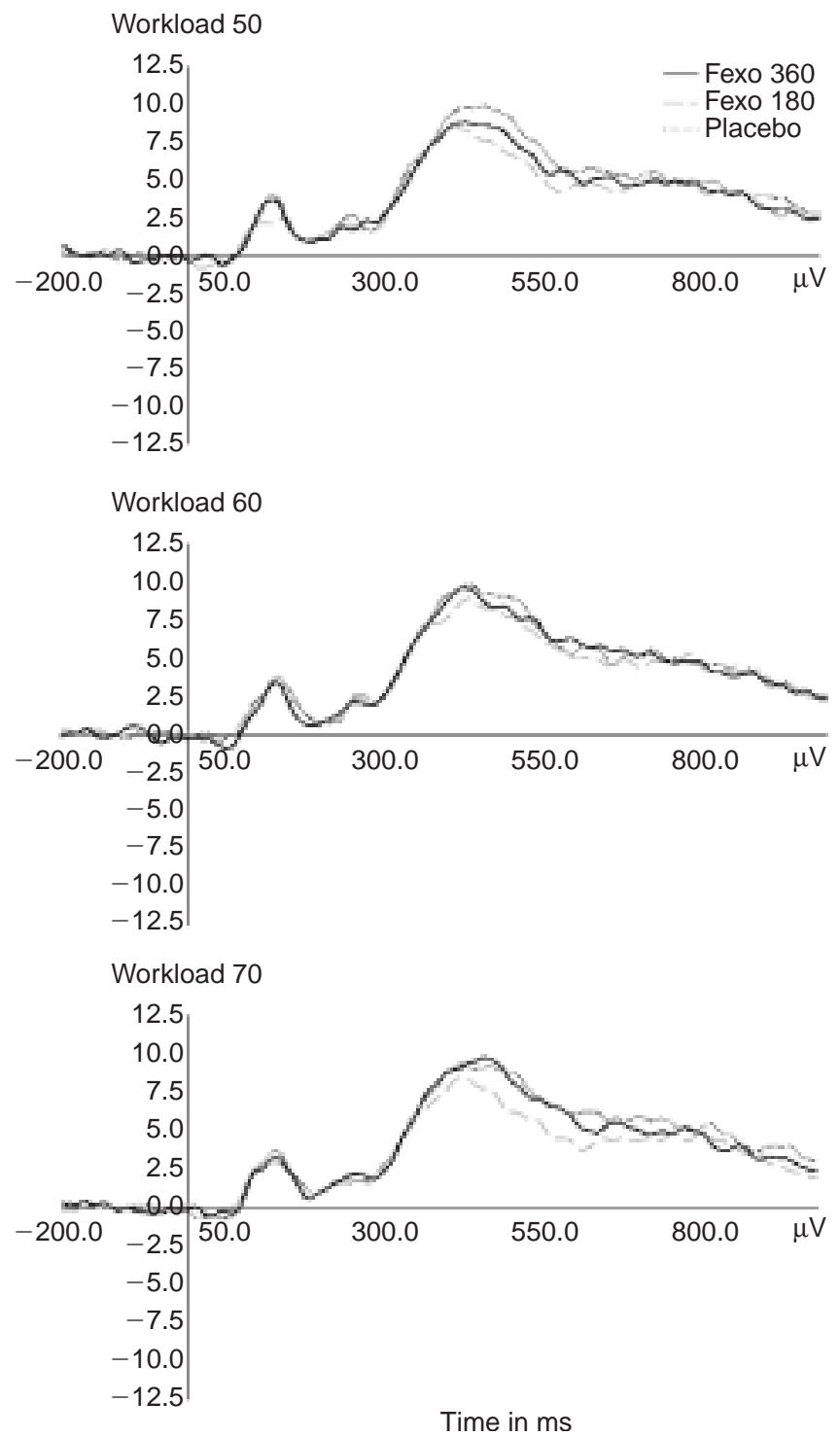

Figure 3 Grand average ERPs showing P3 at Pz for targets and for workload 50, 60 and 70 of the divided attention task. Abbreviations as in Fig. 1.

occurred faster in the harder task conditions, thus fexofenadine appeared to have a facilitating effect on early attentional processing when primary task requirements are higher.

Fexofenadine caused faster P3 latencies in the secondary task of the DAT, while higher workload conditions caused a delayed P3 response. As P3 latency has been linked with stimulus evaluation processes (Duncan-Johnson, 1981; Willard et al., 1994; Smulders et al., 1995; Kok, 1997), these results indicate that when workload is increased, stimulus evaluation time increases, demonstrated by the later $\mathrm{P} 3$ peak. Fexofenadine on the other hand causes the stimulus evaluation process to be completed faster. P3 
(a)

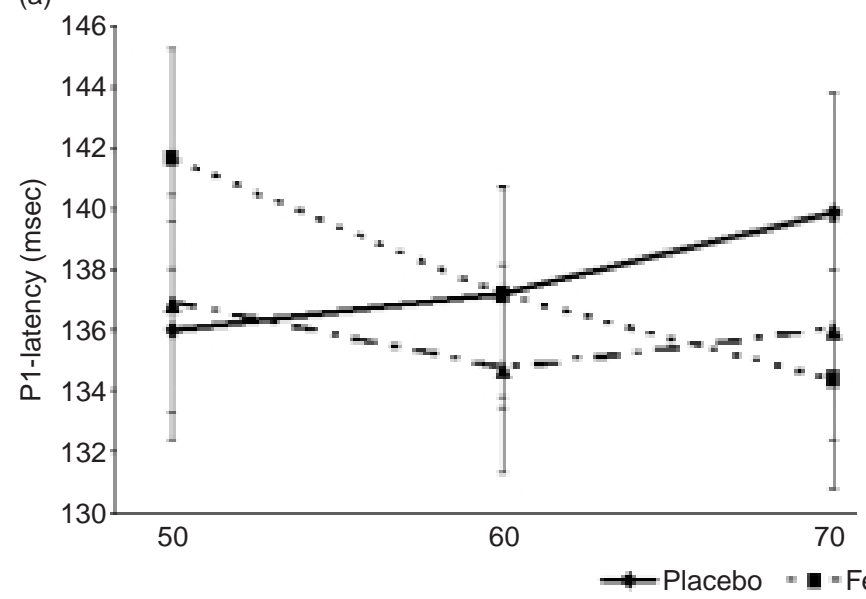

(b)

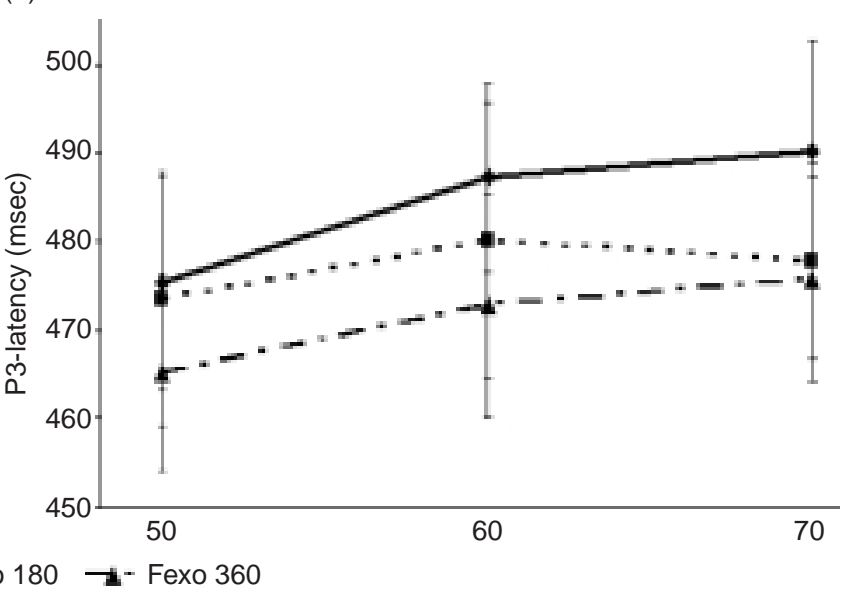

Figure 4 P1-latency (msec) on the secondary task of the DAT (a) and P3-latency (msec) for the targets in the secondary task of the DAT (b). Latencies are given for each workload condition $(50,60,70)$ and for each dose of fexofenadine.

Abbreviations as in figure 1.

amplitude in response to secondary task stimuli was not affected by fexofenadine or workload. Previous studies have demonstrated that P3 amplitude is a measure of the amount of mental capacity that is invested in a task (Kok, 1997). The lack of an effect of workload or fexofenadine on P3 amplitude would therefore indicate that these factors did not affect the amount of mental capacity available for the secondary task. Using an auditory oddball task as primary task and a tracking task as secondary, Wickens et al. (1977) and Isreal et al. (1980) did find a decrease in P3 amplitude in the primary task when introducing this concurrent task, but found no further decrement in P3 when the secondary task became more difficult. It was interpreted that tracking difficulty and oddball task performance are mainly dependent on different processes; with the tracking task relying mostly on responserelated resources, while the oddball task is thought to mainly address perceptual resources (Kok, 1997).

Fexofenadine did not influence performance in the CPT-ax tasks. Only in the difficult version an effect of drug was found on the reaction time; it was however unclear which drug condition caused this effect. The event related potentials measured during the CPT-ax tasks were unaffected by drug treatment. Task manipulations, however, had an effect on event related potentials involved in target processing and target inhibition of the CPT-ax tasks. These effects confirm that stimuli that must be attended to generate larger P3 peaks than stimuli that are to be ignored (Picton, 1992; Coull, 1998). The frontal N2 peak, thought to represent an inhibition process in Go/NoGo tasks, was later and larger when NoGo stimuli did share features with the target letter (e.g. K and $\mathrm{X}$-dot below). This finding points to increased inhibitory effort in conditions in which NoGo stimuli resemble Go stimuli in at least some stimulus features and supports an inhibition hypothesis of the frontal N2 (Jodo and Kayama, 1992).

A stimulant effect of fexofenadine was also demonstrated in the motor choice reaction task. Fexofenadine interacted with task difficulty of the motor choice reaction time and fexofenadine $180 \mathrm{mg}$ caused faster movement times. As there was no effect on initiation or reaction time, this suggests that fexofenadine only affected the purely motor component and not the cognitive aspect of this task.

On the basis of the effects found in the motor choice reaction task and the divided attention task, behaviourally as well as physiologically, it can be concluded that fexofenadine has slightly stimulating properties. Consequently it is evident that fexofenadine has the capability of crossing the blood brain barrier and act centrally. However, it is still unclear by which mechanism fexofenadine stimulates cognitive processes. One hypothesis is that fexofenadine has an effect on the dopamine system, where it blocks the reuptake of dopamine presynaptically, causing an increase in the dopamine availability. This increased dopamine availability could produce effects similar to psychomotor stimulants. The inhibitory effect of antihistamines on the neuronal uptake of dopamine has already been demonstrated in rats and mice (Oishi et al., 1994; Matsunaga et al., 1998) e.g. in the neostriatum and nucleus accumbens (Dringenberg et al., 1998). Evidence for the dopamine reuptake hypothesis is also found in behavioural animal studies reporting antihistamines to increase the rate of fixed interval responding (Bergman and Spealman, 1988) and potentiate conditioned place preference (Suzuki et al., 1999). These effects were probably mediated by dopamine uptake inhibition since the effects attenuated after treatment with dopamine antagonists (Bergman and Spealman, 1988; Suzuki et al., 1999).

In conclusion, the neurophysiological data indicated CNS activation after fexofenadine treatment. However, the stimulant effects of fexofenadine at the behavioural level were minor and only demonstrated in high workload conditions. Together, these results suggest that fexofenadine's centrally activating effects are generally too small in magnitude to produce clinically relevant performance improvement at the behavioural level. 


\section{Acknowledgements}

We thank E. Engelen and Dr N. Muntjewerff for their respective contributions to this study.

\section{References}

Bergman J, Spealman R D (1988) Behavioral effects of histamine H1 antagonists: comparison with other drugs and modification by haloperidol. J Pharmacol Exp Ther 245: 471-478

Bower E A, Moore J L, Moss M, Selby K A, Austin M, Meeves S (2003) The effects of single-dose fexofenadine, diphenhydramine, and placebo on cognitive performance in flight personnel. Aviat Space Environ Med 74: 145-152

Brocke B, Tasche K G, Beauducel A (1996) Biopsychological foundations of extraversion: differential effort reactivity and the differential P300 effect. Personality and Individual Differences 21: 727-738

Clarke C H, Nicholson A N (1978) Performance studies with antihistamines. Br J Clin Pharmacol 6: 31-35

Conners C K (1992) Conners' Continuous Performance Test computer program user's guide. Multi-Health Systems, Toronto

Coull J T (1998) Neural correlates of attention and arousal: insights from electrophysiology, functional neuroimaging and psychopharmacology. Prog Neurobiol 55: 343-361

Dringenberg H C, de Souza-Silva M A, Schwarting R K, Huston J P (1998) Increased levels of extracellular dopamine in neostriatum and nucleus accumbens after histamine $\mathrm{H} 1$ receptor blockade. Naunyn Schmiedebergs Arch Pharmacol 358: 423-429

Duncan-Johnson C C (1981) Young Psychophysiologist Award address, 1980. P300 latency: a new metric of information processing. Psychophysiology 18: 207-215

Duncan-Johnson C C, Donchin E (1977) On quantifying surprise: the variation of event-related potentials with subjective probability. Psychophysiology 14: 456-567

Falkenstein M, Hoormann J, Hohnsbein J (1999) ERP components in Go/Nogo tasks and their relation to inhibition. Acta Psychol (Amst) 101: 267-291

Gengo F M (1996) Reduction of the central nervous system adverse effects associated with antihistamines in the management of allergic disorders: strategies and progress. J Allergy Clin Immunol 98: S319-325

Hindmarch I, Shamsi Z (1999) Antihistamines: models to assess sedative properties, assessment of sedation, safety and other side-effects. Clin Exp Allergy 29: 133-142

Hindmarch I, Shamsi Z, Stanley N, Fairweather D B (1999) A doubleblind, placebo-controlled investigation of the effects of fexofenadine, loratadine and promethazine on cognitive and psychomotor function. Br J Clin Pharmacol 48: 200-206

Houx P J, Jolles J (1993) Age-related decline of psychomotor speed: effects of age, brain health, sex, and education. Percept Mot Skills 76: 195-211

Isreal J B, Chesney G L, Wickens C D, Donchin E (1980) P300 and tracking difficulty: evidence for multiple resources in dual-task performance. Psychophysiology 17: 259-273

Jex H R, McDonnell J D, Phatak A V (1966) A 'critical' tracking task for man-machine research related to the operator's effective delay time. I. Theory and experiments with a first-order divergent controlled element. NASA CR-616. NASA Contract Rep NASA CR 1-105

Jodo E, Kayama Y (1992) Relation of a negative ERP component to response inhibition in a Go/No-go task. Electroencephalogr Clin Neurophysiol 82: 477-482

Kok A (1997) Event-related-potential (ERP) reflections of mental resources: a review and synthesis. Biol Psychol 45: 19-56

Kok A (2001) On the utility of P3 amplitude as a measure of processing capacity. Psychophysiology 38: 557-577
Mangun G R (1995) Neural mechanisms of visual selective attention. Psychophysiology 32: 4-18

Mangun G R, Hillyard S A (1990) Electrophysiological studies of visual selective attention in humans. In Scheibel A B, Wechsler A F (eds), Neurobiology of higher cognitive function. Guilford, New York

Mangun G R, Hillyard S A (1995) Mechanisms and models of selective attention. In Rugg M D, Coles M G H (eds), Electrophysiology of mind. Event-related brain potentials and cognition. Oxford University Press, Oxford

Matsunaga K, Sato T, Shuto H, Tsuruta Y, Suemaru K, Gomita Y, Oishi R (1998) Inhibition of neuronal dopamine uptake by some antiallergic drugs. Eur J Pharmacol 350: 165-169

Mattila M J, Kuitunen T, Pletan Y (1992) Lack of pharmacodynamic and pharmacokinetic interactions of the antihistamine ebastine with ethanol in healthy subjects. Eur J Clin Pharmacol 43: 179-184

Mertens R, Polich J (1997) P300 from a single-stimulus paradigm: passive versus active tasks and stimulus modality. Electroencephalogr Clin Neurophysiol 104: 488-497

Moskowitz H (1973) Laboratory studies of the effects of alcohol on some variables related to driving. Journal of Safety Research 5: 185-192

Moskowitz H, Burns M B (1988) Effects of terfenadine, diphenhydramine, and placebo on skills performance. Cutis 42: 14-18

Nicholson A N, Stone B M, Turner C, Mills S L (2000) Antihistamines and aircrew: usefulness of fexofenadine. Aviat Space Environ Med 71: 2-6

O’Hanlon J F, Ramaekers J G (1995) Antihistamine effects on actual driving performance in a standard test: a summary of Dutch experience, 1989-94. Allergy 50: 234-342

Oishi R, Shishido S, Yamori M, Saeki K (1994) Comparison of the effects of eleven histamine H1-receptor antagonists on monoamine turnover in the mouse brain. Naunyn Schmiedebergs Arch Pharmacol 349: $140-144$

Onodera K, Yamatodani A, Watanabe T, Wada H (1994) Neuropharmacology of the histaminergic neuron system in the brain and its relationship with behavioral disorders. Prog Neurobiol 42: 685-702

Onoe H, Yamatodani A, Watanabe T, Ono K, Mochizuki T, Wada H, Hayaishi O (1992) Prostaglandin E2 and histamine in the posterior hypothalamus. J Sleep Res 1: 166

Passalacqua G, Bousquet J, Bachert C, Church M K, Bindsley-Jensen C, Nagy L, Szemere P, Davies R J, Durham S R, Horak F, Kontou-Fili K, Malling H J, van Cauwenberge P, Canonica G W (1996) The clinical safety of H1-receptor antagonists. An EAACI position paper. Allergy 51: $666-675$

Picton T W (1992) The P300 wave of the human event-related potential. J Clin Neurophysiol 9: 456-479

Polich J, Kok A (1995) Cognitive and biological determinants of P300: an integrative review. Biol Psychol 41: 103-146

Ramaekers J G, O’Hanlon J F (1994) Acrivastine, terfenadine and diphenhydramine effects on driving performance as a function of dose and time after dosing. Eur J Clin Pharmacol 47: 261-266

Reinberg A, Levi F, Guillet P, Burke J T, Nicolai A (1978) Chronopharmacological study of antihistamines in man with special references to terfenadine. Eur J Clin Pharmacol 14: 245-252

Ridout F, Shamsi Z, Meadows R, Johnson S, Hindmarch I (2003) A single-center, randomized, double-blind, placebo-controlled, crossover investigation of the effects of fexofenadine hydrochloride $180 \mathrm{mg}$ alone and with alcohol, with hydroxyzine hydrochloride $50 \mathrm{mg}$ as a positive internal control, on aspects of cognitive and psychomotor function related to driving a car. Clin Ther 25: 1518-1538

Riedel W J, Ramaekers G, Uiterwijk M M, O’Hanlon J F (1990) Higher doses of terfenadine and loratadine: acute and subchronic effects on 
psychomotor and actual driving performance. Institute for Drugs, Safety and Behavior, University of Limburg. IGVG 90-12

Rombaut N E I, Hindmarch I (1994) Psychometric aspects of antihistamines: a review. Human Psychopharmacology 9: 157-169

Rugg M D, Milner A D, Lines C R, Phalp R (1987) Modulation of visual event-related potentials by spatial and non-spatial visual selective attention. Neuropsychologia 25: 85-96

Semlitsch H V, Anderer P, Schuster P, Presslich O (1986) A solution for reliable and valid reduction of ocular artifacts, applied to the P300 ERP. Psychophysiology 23: 695-703

Simons F E (1994) H1-receptor antagonists. Comparative tolerability and safety. Drug Saf 10: 350-380

Smulders F T, Kok A, Kenemans J L, Bashore T R (1995) The temporal selectivity of additive factor effects on the reaction process revealed in ERP component latencies. Acta Psychol (Amst) 90: 97-109

Snyder S H, Snowman A M (1987) Receptor effects of cetirizine. Ann Allergy 59: 4-8

Suzuki T, Mori T, Tsuji M, Nomura M, Misawa M, Onodera K (1999) Evaluation of the histamine H1-antagonist-induced place preference in rats. Jpn J Pharmacol 81: 332-338

Taylor M J (2002) Non-spatial attentional effects on P1. Clin Neurophysiol 113: 1903-1908

Theunissen E L, Vermeeren A, van Oers A C M, van Maris I, Ramaekers J G (2004) A dose ranging study of the effects of mequitazine on actual driving, memory and psychomotor performance as compared to dexchlorpheniramine, cetirizine and placebo. Clin Exp Allergy 34: 250-258

Vermeeren A, O'Hanlon J F (1998) Fexofenadine's effects, alone and with alcohol, on actual driving and psychomotor performance. J Allergy Clin Immunol 101: 306-311
Vermeeren A, Ramaekers J G, O'Hanlon J F (2002) Effects of emedastine and cetirizine, alone and with alcohol, on actual driving of males and females. J Psychopharmacol (Oxf) 16: 57-64

Vuurman E F, Uiterwijk M M, Rosenzweig P, O'Hanlon J F (1994) Effects of mizolastine and clemastine on actual driving and psychomotor performance in healthy volunteers. Eur J Clin Pharmacol 47: 253-259

Vuurman E F P M, Rikken G H, Muntjewerff N D, de Halleux F, Ramaekers J G (2004) Effects of desloratadine, diphenhydramine, and placebo on driving performance and psychomotor performance measurements. Eur J Clin Pharmacol 60: 307-313

Weiler J M, Bloomfield J R, Woodworth G G, Grant A R, Layton T A, Brown T L, McKenzie D R, Baker T W, Watson G S (2000) Effects of fexofenadine, diphenhydramine, and alcohol on driving performance. A randomized, placebo-controlled trial in the Iowa driving simulator. Ann Intern Med 132: 354-363

Wickens C, Kramer A, Vanasse L, Donchin E (1983) Performance of concurrent tasks: a psychophysiological analysis of the reciprocity of information-processing resources. Science 221: 1080-1082

Wickens C D, Isreal J B, Donchin E (1977) The event-related cortical potential as an index of task workload. In Neal A S, Palased R F (eds), Proceedings of the Human Factors Society 21st annual meeting. Human Factors Society, Santa Monica

Willard J, Johnson M, Rosenfeld J P (1994) Interaction of oddball probability and primary task type on P300 in the dual-task paradigm. Biofeedback Self Regul 19: 13-24 